\title{
The Relationship Between Parenting Styles and Substance Use Among University Students
}

\author{
Zackaria I. Niari ${ }^{* a}$, Danielle Dicke, ${ }^{b, d}$, Amy Adkins, ${ }^{b, d}$, Megan Cooke $e^{* e}$ \\ ${ }^{a}$ Department of Biology, Virginia Commonwealth University, Richmond, $V A$ \\ ${ }^{b}$ Department of Psychology, Virginia Commonwealth University, Richmond, VA \\ 'Department of Human and Molecular Genetics, Virginia Commonwealth University, Richmond, VA \\ ${ }^{d}$ College Behavioral and Emotional Health Institute, Virginia Commonwealth University, Richmond, VA \\ ${ }^{e}$ Virginia Institute for Psychiatric and Behavioral Genetics, Virginia Commonwealth University, Richmond, VA \\ Student:niazizi@vcu.edu* \\ Mentors:cookem@vcu.edu*,dickdm@vcu.edu,adkinsae@vcu.edu
}

\begin{abstract}
Parenting styles are important in the behavioral development of adolescents. The environment created by the parent, in regards to communication with their child and level of independence given to their child, may influence the child's susceptibility to risk behaviors. This study examines the relationship between parenting style and substance use among university students. We hypothesized that university students exposed to lower levels of autonomy granting (AG) or parental involvement (PI) parenting styles would have an increased likelihood of alcohol and nicotine use. We also hypothesized that religiosity, parental education level, ethnicity, and gender would act as moderators of parenting styles and alcohol and nicotine use. Data from a diverse university-wide sample was collected in the fall semester of the student's freshman year from 2011-2014 (N = 9889, 61.5\% female). Results demonstrated that AG had a significant, negative association with alcohol use $(B=-0.033, p=0.006)$ and nicotine use $(B=-0.066, p<0.001)$. All moderators were found to be significant predictors of alcohol use, however only father education level demonstrated a borderline significant moderation of the relationship between PI and alcohol use. Religiosity, Black race, Asian race, and gender were found to be significant predictors of nicotine use. Only gender moderated the association between PI and nicotine use. Even though alcohol and nicotine use and AG were associated, our results indicate that once students enter university, previous parenting style does not have a strong effect on alcohol and nicotine use behaviors in our sample.
\end{abstract}

\section{KEYWORDS}

Parenting Styles; University Students; Risky Behaviors; Autonomy Granting; Parental Involvement; Alcohol; Nicotine; Drug; Behavioral Biology; Substance Use

\section{INTRODUCTION}

Frequent alcohol and nicotine use has been found to have negative consequences in terms of physical health, mental health, and social relationships., 2 Nicotine use has been shown to have negative effects on the physical health of individuals, such as heart problems and lung cancer. ${ }^{1}$ In addition, alcohol use among university students can lead to a range of consequences such as academic impairment, blackouts, sexual coercion/rape victimization, property damage, fights, and vehicular related death.3,4 In order to form better intervention and education plans, it is important to understand and explore the pathways to university student risk behaviors.

Parenting styles are important in the behavioral development of adolescents. It has been shown that parenting style could play a role in whether or not adolescents and college students are willing to participate in risky behaviors, such as alcohol use, nicotine use, and illicit drug use. ${ }^{5,6}$ Lack of communication between parent and adolescent is one of the factors in the development of risk behaviors and substance abuse. ${ }^{5}$ Studies have shown that certain parenting styles can influence issues such as self-concealment, resulting in the adolescent having less self-regulatory resources to maintain control of drinking. ${ }^{7}$ The diminished self-regulation can lead to impaired control over alcohol consumption and alcohol-related problems. ${ }^{7}$ Presence of an authoritative mother is directly linked to more secrets between the parent and adolescent, while having an authoritative father is directly linked to fewer secrets. ${ }^{7}$

As discussed above, previous studies have shown that parenting styles may influence the development of risk behaviors in adolescents. ${ }^{5,8}$ Therefore, while it is clear that parenting styles play a large role in adolescent behavior, far less is known regarding the relationship between parenting style and substance use in university students/emerging adulthood. The transition from high school to university is a key developmental milestone and has the potential for change in behavior and personal growth. ${ }^{6}$ This is primarily because university students, who generally live on campus in dormitories or on their own, are in an environment where parental supervision is limited while opportunities to engage in risky behaviors are abundant. ${ }^{6}$ Some of the risky behaviors university students can partake in include alcohol use, tobacco use, and illicit drug use. ${ }^{9,7}$ The transition to university, in 
combination with parenting style, could result in increased risk behaviors among freshman in a university setting and thus emphasize the importance of examining these relationships.

There are several other family level factors that could affect the relationship between parenting and substance use, such as religiosity, gender, ethnicity, parents' level of education. Some religions preach against the use of substances such as alcohol, nicotine, and marijuana because it is viewed as defiling of one's body and considered sinful. ${ }^{10}$ In a study of university students in Northern Ireland, Wales and England, it was found that religiosity and abstaining from drug use were positively associated. ${ }^{9}$ Therefore, it is important to examine whether religiosity may play a role in freshman university student substance use outcomes. Parents' level of education is important in that it is usually negatively associated with financial stress. ${ }^{11}$ Occasional drug use has been known to be prevalent among students who have financial burdens and economic instability. ${ }^{9}$ 'This prevalence could be a result of environmental factors influenced by socio-economic status, such as home and school environment. ${ }^{11}$ Gender of the university student is important when examining parent-child dynamics; when the parent is the same sex as the subject, parenting style is found to be significantly related to self-regulation. This is crucial because self-regulation is found to be protective against alcohol use and abuse. ${ }^{8}$ A permissive parent, of the same sex as the subject, is found to be negatively associated with good selfregulatory processes for both men and women, while an authoritative parent, of the same sex as the subject, is found to be associated with positive levels of self-regulation among the subjects. ${ }^{8}$ In addition, previous studies have demonstrated that drinking patterns and risky drinking differ among ethnic groups and genders. ${ }^{12}$

While there are various types of parenting styles, from authoritative parenting to neglectful parenting; ${ }^{13}$ the current study focuses on the Steinberg Parenting styles. Autonomy Granting (AG) is a form of parenting in which parents encourage their kids to express their own ideas and thoughts without expressing psychological control and disapproval. ${ }^{14}$ Another dimension of parenting is Parental Involvement (PI), which entails the involvement of the parent within school functions and their awareness of the adolescent's peers, feelings, and interests. ${ }^{14}$ The lack of or limited exposure to either parenting style indicates a form of parenting in which the adolescent's views and opinions are not heard and there is little involvement invested in the adolescent. The current study aims to examine whether there is a connection between parenting style and university student alcohol use or nicotine use. In addition, it seeks to test whether there are associations of alcohol and nicotine use with religiosity, ethnicity, gender, and education level of parents. Our study hypothesis is that if parents of a university student exhibit a lower degree of PI and $A G$, then there will be an increase in the frequency of alcohol use or nicotine use by the university student. If such a relationship between parenting style and university student alcohol/nicotine use exists, then we hypothesize that the relationship will be stronger for those with low religiosity and parent education level, and it will be stronger for males and minority groups.

\section{METHODS AND PROCEDURES}

\section{Sample}

The sample for this study is derived from the Spit for Science research project, IRB permission number: HM13352. This project is a university-wide research study, at a large, urban university, that focuses on understanding the genetic and environmental influences on the development of risk behaviors in college students. ${ }^{15}$ The majority of students reported that they live in oncampus housing $(88.1 \%)$. Programs organized by the residential life and housing are available. Freshman students, ages 18 or older, were recruited in the Fall from 2011 to 2014 by e-mail invitation. ${ }^{15}$ After consenting to participate online, students completed a survey containing questions that assessed personality and behavior, as well as family environment and experiences growing up. After completion of the survey, participants collected $\$ 10$ as payment and were given the option to submit their saliva sample for a second payment of $\$ 10 .{ }^{15}$

Data from 9889 participants were used from the fall cohorts of 2011, 2012, 2013, and 2014. Of the participants, 6040 were female $(61.5 \%)$. The mean age of the students was $18.50(\mathrm{SD}=0.43)$. Of the participants, 6114 reported that neither of their biological parents had a drinking problem (72.4\%). The ethnic breakdown of the participants was: White $(N=4881,50.1 \%)$, Black/African American $(N=1873,19.2 \%)$, Asian $(N=1615,16.6 \%)$, multiracial $(N=617,6.3 \%)$, Hispanic/Latino $(N=594,6.1 \%)$, Native Hawaiian/Pacific Islander $(N=67,0.7 \%)$, American Indian/Native Alaskan $(N=51,0.5 \%)$. The ethnic breakdown was representative of the university's population.

\section{Protocol}

Study data were collected using REDCap (Research Electronic Data Capture) tools hosted at Virginia Commonwealth University. ${ }^{16}$ This secure, web-based application is designed to support data capture for research studies.

\section{Measures}

Parenting style was measured by a set of six statements, as obtained from Steinberg et al. 1992 ${ }^{14}$, with a four-point response scale of: "Strongly Agree," "Agree Somewhat," "Disagree Somewhat," and "Strongly Disagree."

Statements measuring the parent's AG included: "My parents said that I should give in on arguments rather than making people angry," "My parents told me that their ideas were correct and that I should not question them," and "My parents acted cold and unfriendly if I did something they didn't like." Statements measuring PI included: "My parents helped me with my school work if 
there was something I didn't understand," "My parents knew who my friends were," and "My parents spend time just talking with me."

Separate sum scores, with a range of 3-12, were created for the AG and PI parenting styles to measure the degree of the parenting styles. Variables were then mean centered.

Biological parent drinking problem was measured by two questions: "Do you think your biological mother has ever had a drinking problem?" and "Do you think your biological father has ever had a drinking problem?" Drinking problem was defined as "...his/her drinking caused problems at home, at work, with his/her health, with the police, or that he/she received alcohol treatment." Responses were a binary "No," or "Yes."

The biological parent drinking problem variable was created by considering the data from both questions to assess the percentage of students that reported neither of their biological parents having drinking problems.

Alcohol use was measured by questions based off the AUDIT-C. ${ }^{17}$ Alcohol use frequency was measured by the question "How often do you have a drink containing alcohol?" with a four-point response scale of: "Never," "Monthly or less," "2 to 4 times a month," "2 to 3 times a week," and "4 or more times a week." The response "Never" was recoded as 0 days per month, "Monthly or less" as 1 day per month, "2 to 4 times a month" as 3 days per month, "2 to 3 times a week" as 10 days per month, and " 4 or more times a week" as 16 days per month.

Alcohol use quantity was measured by the question "How many drinks containing alcohol do you have on a typical day when you are drinking?" with a five-point response scale of: " 1 or 2 ," "3 or 4," "5 or 6," “7, 8, or 9," and " 10 or more." The response " 1 or 2" was recoded as 1.5 drinks, " 3 or 4" as 3.5 drinks, " 5 or 6" as 5.5 drinks, “7, 8, or 9" as 8 drinks, and " 10 or more" as 10 drinks. The alcohol variable was created by multiplying the recoded data from both questions to assess the quantity of drinks per month. The variable underwent log transformation to better approximate a normal distribution.

Nicotine use was measured by questions based off the IMPACTS study at University of Missouri. ${ }^{18}$ Nicotine use was measured by the question "How frequently did you smoke [cigarettes, cigars, smokeless tobacco products, or hookah] in the last 30 days?" with a seven-point response scale of: "I didn't smoke any [cigarettes, cigars, smokeless tobacco products, or hookah] in the last month," "once or twice," "A few days (3 to 4 days a month)," "A couple of days a week (5 to 11 days a month)," "Three times a week (12 to 14 days a month)," "Most days of the week (15 to 25 days a month)," and "Daily or almost daily (26 to 30 days a month)."

Four questions, with the same responses, regarding nicotine use in different forms (i.e. cigarette, cigars, smokeless tobacco, and hookah) were combined by selecting the highest use of each nicotine product to evaluate overall nicotine use.

Gender was measured by the binary response of: "Male," and "Female."

Ethnicity was measured by the question "Which one of these groups best describes you?" with an eight-point response scale of:

"American Indian/Alaska Native," "Asian," "Black/African American," "Hispanic/Latino," "More than one race," "Native Hawaiian/Other Pacific Islander," "Unknown," and "White."

A binary variable of White and Black, White and Asian, and White and Hispanic/Latino was created to analyze ethnicity with white as the reference group.

Religiosity was measured by two questions, as obtained from Kendler et al. 1997:19 "In general, how important are your religious and spiritual beliefs in your daily life?" and "When you have problems or difficulties in your family, work, or personal life, how often do you seek spiritual comfort?"

Responses for the first question were on a four-point scale of: "Very important," "Somewhat important," "Not very important," and "Not at all important." Responses for the second question were on a four-point scale of: "Almost always," "Sometimes," "Rarely," and "Never."

A combined sum score, of a range of 2-8, was created to determine the degree of religiosity. Variables were then mean centered. Education level of parents was measured by two questions: "The woman who functioned as mother; How far in school did she go?" and "The man who functioned as father; How far in school did he go?"

Responses in regards to mother/father's level of education were based on 12 possible answer choices that were recoded. The response "He/She never went to school," was recoded as 0 years. Responses "He/She went to school, but I don't know what level," and "There was no one who functioned as a mother/father in my household" was recoded as missing. "Eighth grade or less" was recoded as 8 years. "More than eighth grade, but did not graduate from high school," and "Went to business, trade or vocation school instead of high school" were recoded as 10 years. "High school graduate," and "Completed a GED" were recoded as 12 years. "Went to business, trade, or vocational school after high school" was recoded as 13 years. "Went to college, but did not graduate" was recoded as 14 years. "Graduated from a college or university" was recoded as 16 years. "Professional training beyond a four-year college or university" was recoded as 20 years. The variable was then centered.

\section{Statistical Analysis}

Statistical analysis was conducted using the $22^{\text {nd }}$ version of the IBM SPSS Software. Linear regressions were used to analyze the relationship between AG and alcohol use, and between PI and alcohol use. Ordinal regressions were used to analyze the relationship between AG and nicotine use, and PI and nicotine use. Ordinal regressions were used for determining the relationship with nicotine use because of the ordinal nature of the nicotine use data. 
Interaction variables were created by cross-multiplying parenting styles with each moderator. The interaction variables were then used in a regression model to determine if the moderators interacted with each parenting style to produce an effect on nicotine or alcohol use. Linear regressions were conducted to determine the relationship between the moderators, biological parent drinking problem, and alcohol use, while ordinal regressions were conducted to determine the relationship between the moderators and nicotine use. To better gain an understanding of the relationship between the covariates and alcohol and nicotine use, linear regression analysis and ordinal regression analysis were conducted respectively.

\section{RESULTS}

Sample Overview

The participants in our sample had an average of 14.12 drinks per month. On average, participants used nicotine products one to four days a month. Table 1 below presents the mean, standard deviations, and sample size of the other variables.

\begin{tabular}{|c|c|c|c|c|}
\hline Measure & $n$ & Mean & Standard Deviation & Percent Endorsed \\
\hline Age & 7902 & 18.5 & 0.43 & \\
\hline \multicolumn{5}{|l|}{ Parenting Style } \\
\hline Autonomy Granting & 7369 & 8.17 & 2.18 & \\
\hline Parental Involvement & 7399 & 9.61 & 2.08 & \\
\hline Frequency of Alcohol Use & 4240 & 14.12 & 23.35 & \\
\hline Frequency of Nicotine Use & 7077 & 2.14 & 1.74 & \\
\hline Religiosity & 9193 & 4.93 & 2.10 & \\
\hline \multicolumn{5}{|l|}{ Parental Education } \\
\hline Mother Education & 9503 & 15.24 & 3.00 & \\
\hline Father Education & 9127 & 15.40 & 3.24 & \\
\hline Biological Parent Drinking & 8456 & & & $27.6 \%$ \\
\hline \multicolumn{5}{|l|}{ Ethnicity } \\
\hline White & 4881 & & & $50.1 \%$ \\
\hline Black & 1873 & & & $19.2 \%$ \\
\hline Asian & 1615 & & & $16.6 \%$ \\
\hline Hispanic & 594 & & & $6.1 \%$ \\
\hline \multicolumn{5}{|l|}{ Gender } \\
\hline Male & 3780 & & & $38.5 \%$ \\
\hline Female & 6040 & & & $61.5 \%$ \\
\hline
\end{tabular}

Table 1 demonstrates a mean of higher than 15 for both parents' education, meaning that the average parent in our sample attended some college or completed college.

\section{Parenting Style and Substance Use}

Table 2 demonstrates the relationships between the parenting styles and alcohol use when biological parent drinking problem, religiosity, mother education, father education, ethnicity, and gender were controlled. The relationship between parenting style and nicotine use is also demonstrated with religiosity, mother education, father education, ethnicity, and gender controlled. Linear regression analysis was conducted between parenting style, moderators, and alcohol use. There was a significant, weak, and negative relationship between AG and alcohol use $(B=-0.033, p=0.006)$. Ordinal regression analysis was conducted between parenting style, moderators, and nicotine use. Results revealed a significant, weak, negative relationship between AG and nicotine use $(B=-0.037, p<0.001)$.

\begin{tabular}{|c|c|c|c|}
\hline Variable & $B$ & $S E B$ & $P$-value \\
\hline \multicolumn{4}{|l|}{ Alcohol Use* } \\
\hline Parenting Style: Involvement & 0.012 & 0.014 & 0.385 \\
\hline $\begin{array}{l}\text { Parenting Style: Autonomy } \\
\text { Granting }\end{array}$ & -0.033 & 0.012 & $0.006^{* *}$ \\
\hline \multicolumn{4}{|l|}{ Nicotine Use } \\
\hline Parenting Style: Involvement & -0.012 & 0.014 & 0.381 \\
\hline $\begin{array}{l}\text { Parenting Style: Autonomy } \\
\text { Granting }\end{array}$ & -0.066 & 0.013 & $<0.001^{* *}$ \\
\hline
\end{tabular}




\section{Moderators}

Linear regression analysis was used to analyze the relationship between moderators (gender, ethnicity, religiosity, parental education), biological parent drinking problems, and alcohol use. Religiosity, Black race, Asian race, and female gender were negatively associated with alcohol use ( $B$ range: $-0.051--0.667, p=<0.001)$, while biological parent drinking problem and father education was positively associated with alcohol use $(B$ range: $0.144-0.023$, $p$ range: $<0.001-0.015)$. Mother education was found to be positively associated with alcohol use under Autonomy Granting. Ordinal regression analysis was conducted to analyze the relationship between the moderators and nicotine use. There was a moderate relationship between all moderators, except, mother education level, father education level, and Hispanic/Latino ethnicity and nicotine use $(p$ range: $<0.001-0.005)$. Religiosity demonstrated a negative association with nicotine use ( $B$ range: $-0.10--0.107, p<0.001)$. Being male, and white race were positively associated with nicotine use ( $B$ range: $0.419-0.799, p<0.001)$.

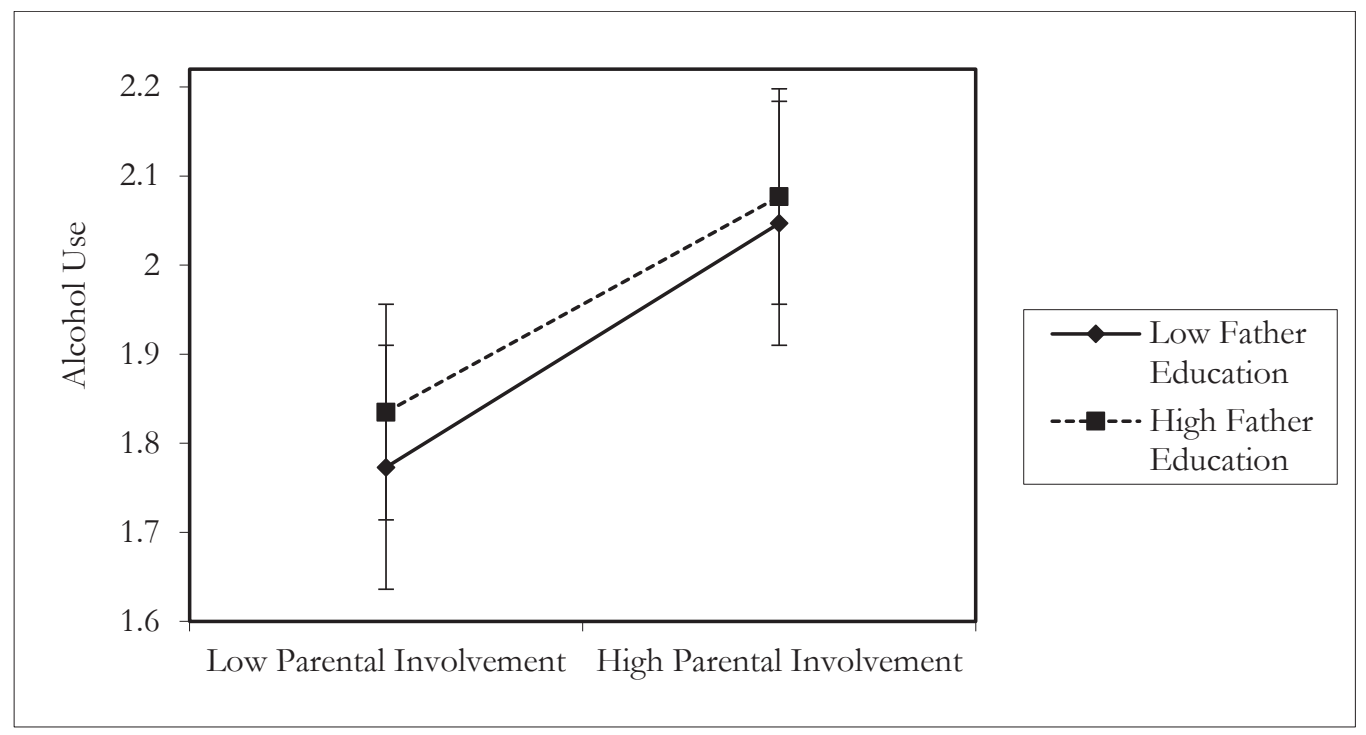

Figure 1. Line Graph Demonstrating Father Education Moderation of Parental Involvement and Alcohol Use \pm SEM.

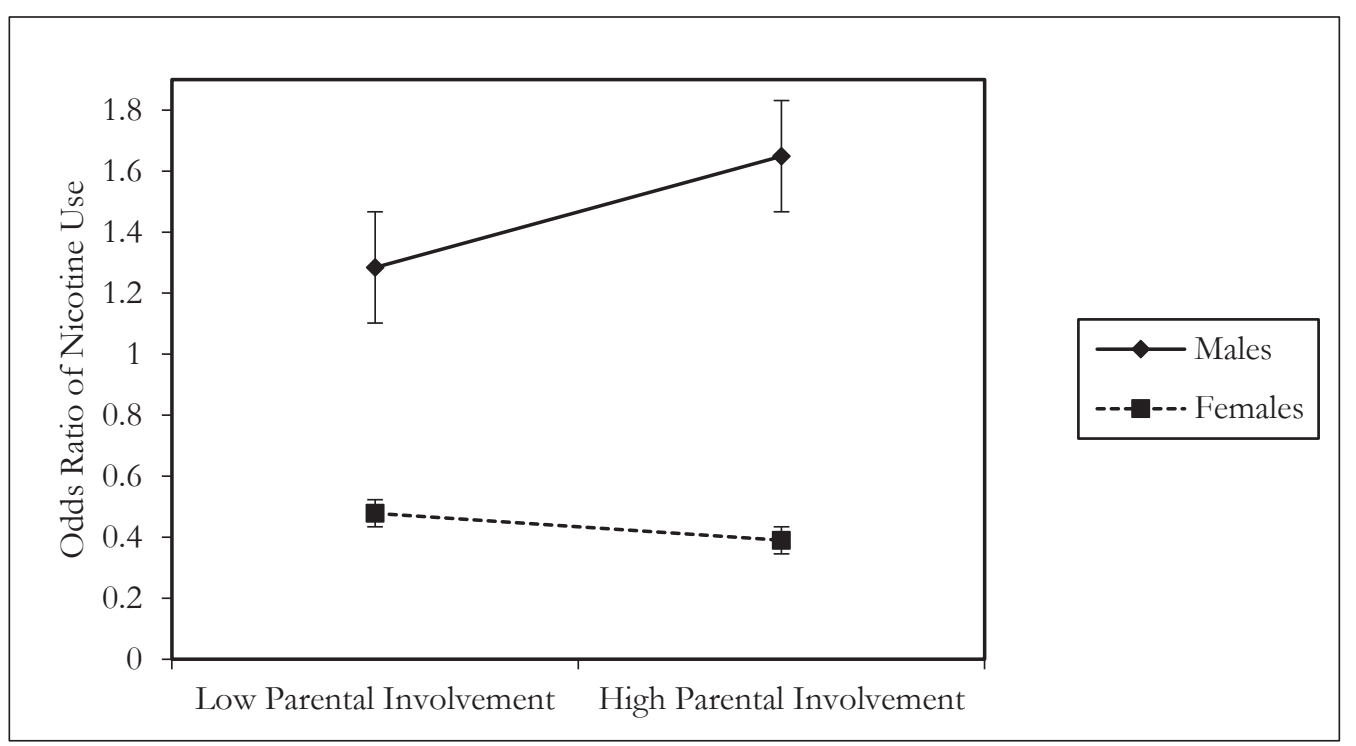

Figure 2. Line Graph Demonstrating Gender Moderation of Parental Involvement and Nicotine Use \pm SEM.

The main effect of father's education on alcohol use was a significant, weak, positive relationship $(B=0.023, p$ range: $0.015-$ 0.018). As demonstrated by Figure 1, father education level was observed to have a borderline significant, weak, negative moderation between PI and alcohol use $(B=-0.008, p=0.056)$, meaning that under high parental involvement there is greater alcohol use across both parent's education levels. Under high father education, there is greater alcohol use across PI levels. The difference of drinking levels is greater between education levels under low PI when compared to high PI. Meaning that, there is 
less drinking among students who reported low PI and low father education than those that reported low PI and high father education.

The main effect of gender on nicotine use was observed to have a significant, moderate, positive relationship $(B=0.440, p=<$ 0.001). We found no significant moderators of AG and alcohol use, as well as AG and nicotine use. Only gender demonstrated moderation between PI and nicotine use; a significant, weak, negative moderation $(B=-0.094, p=0.001)$, meaning that Males with higher levels of PI were associated with higher levels of nicotine use, while Females with higher levels of PI were associated with lower levels of nicotine use. Overall, Females had lower levels of nicotine use than Males. Gender moderation of PI and nicotine use is shown by Figure 2.

\section{DISCUSSION}

This study examined the relationship between parenting styles and alcohol and nicotine use outcomes within a large and diverse group of university students. In addition, the current study sought to test potential moderating factors of the relationship between parenting styles and alcohol and nicotine use such as religiosity, ethnicity, gender, and parent education level. We found that there was no significant relationship between PI and alcohol and nicotine use. AG demonstrated a negative association with alcohol and nicotine use, however it was a weak association. Based on previous research parenting style may play a bigger role in adolescents' substance use prior to college; however, the influence may decrease once they go to university. This could be due to the emerging adult no longer living with their parents and thus being more susceptible to peer influences. The finding is consistent with previous findings demonstrating that parenting style may be less important in the development of early adult substance use. ${ }^{20}$ These results contradict the study by Hartman and colleagues, but this may not be surprising due to the differences between our studies. ${ }^{7}$ Hartman and colleagues focused on the effect of the parenting styles of each individual parent on the university student, while our study focused on the combined effect of parenting styles of both parents. This difference is important to note because other factors, such as gender of the parent, could influence the results.

All moderators (religiosity, ethnicity, gender, and mother/father education level) were found to be significant predictors of alcohol use. Other studies reveal similar results. For example, El Ansari and colleagues found religiosity to have a positive association with the lack of drug use among university students. ${ }^{9}$ Similarly, our analysis demonstrated a negative association of religiosity and alcohol use, the same results were found concerning the relationship between religiosity and nicotine use. However, the El Ansari and colleagues' study was focused more on illicit drug use, whereas our study was aimed towards alcohol and nicotine use. Alcohol, nicotine, and other illicit drugs are all considered psychoactive substances. The abuse of such substances lead to drug dependence. ${ }^{21}$ Therefore, the findings may support each other. We found a significant, moderate, negative relationship between gender and alcohol and nicotine use, indicating that females smoke and drink less than males. This pattern is consistent with past findings in which males were found to use drugs twice as often as females. ${ }^{9}$

Analysis of moderation demonstrated father education level to have a borderline significant, but weak, negative moderating effect between PI and alcohol use. Students whose fathers have high education level drink more than students with low father education level across both PI levels. However, difference between drinking levels was found to be greater between education levels under low PI compared to high PI. Droomers and colleagues also assessed the association between occupational level of the father and high alcohol consumption in adolescents ages 11 to $21 .^{22}$ In addition, the study looked to find factors that explained the association between father occupation level and adolescent drinking. In contrast to our findings, Droomers and colleagues, found that low father occupation, and low parental attachment has a significant increase in the odds of high alcohol consumption. Parental Attachment was assessed in the Droomers and colleagues article using the Inventory of Parent and Peer Attachment (IPPA) scale developed by Armsden and Greenburg, 1987.23 The scale measures of the IPPA had a degree of similarity with our scales as they evaluated Alienation, Communication, and Trust. Droomers and colleagues' finding is still relevant because it assesses communication and awareness of the child's emotions, which is also evaluated in PI. Humensky carried out a study to examine the relationship between adolescent socioeconomic status (measured by parental education and household income) and adolescent substance use (alcohol and illicit drugs). ${ }^{24}$ Findings demonstrated a higher association between adolescent binge drinking, marijuana, and cocaine use when adolescent socioeconomic status was high. ${ }^{24}$ Since higher levels of education are associated with high socioeconomic status, ${ }^{11}$ it could explain the consistently high alcohol use among participants of higher father education level, compared to participants of lower father education level, in both low and high PI. Nonetheless, it is perplexing to find that low father education and low PI are associated with less alcohol usage among university students.

Gender was found to demonstrate a significant, weak, negative moderation between PI and nicotine use. Females tended to have less nicotine use when under both low and high PI. Overall, male participants who reported high PI seemed to have significantly greater nicotine use compared to females who reported high PI. The higher nicotine use among males could be explained by a study conducted by Carroll and colleagues. ${ }^{25}$ This study examined smoking in college students and the results revealed that males were more likely to be current smokers than females. In addition, one of the aspects of PI is parent-adolescent communication and discussion. ${ }^{26} \mathrm{~A}$ previous study with Bahamian adolescents has found that problematic parent-adolescent communication demonstrated a consistent increase in substance use behaviors, sexual risk behaviors, and delinquent behaviors. ${ }^{26}$ Since males demonstrated greater nicotine use than females who reported high PI, it can be speculated that gender differences play a role in the quality of parent-adolescent communication. This can be explained by a study conducted on Italian adolescents which found 
that female adolescents reported more open communication with their parents, especially with their mothers, than male adolescents. ${ }^{27}$ The increase in problematic parent-adolescent communication could explain the higher nicotine use in males who reported high PI.

\section{CONCLUSIONS}

The data used in this study is from a large survey that focuses on understanding the genetic and environmental conditions that lead to substance use in university students. This, along with the representative, diverse sample and appropriate age group, are strengths of this study. An important limitation is that this study examined students around the time of matriculation into university. Entering university is a time in which students have obtained a new degree of freedom and have the opportunity to experiment with risk behaviors. By following the participants throughout their time in university we would have been able to analyze data from their alcohol and nicotine habits, rather than just obtaining data that may have been from experimenting and trying to gain new experiences. Another important limitation is that this study did not have the data to control nicotine relationships for parental nicotine use, as done with alcohol relationships.

Future directions of this study could be to assess whether or not other factors influence alcohol and nicotine use such as home environment, conflict, extracurricular activities, and peer usage. Other studies could aim to obtain parental report of parenting styles and use the data, in addition to the participant's report on parenting style, to determine the relationship with alcohol and nicotine use among the participants. In addition, the study could examine alcohol and nicotine use over time. Examining these factors is important in that it could help better inform the population regarding the outlying factors that associate with alcohol and nicotine use. It could also help improve treatment and intervention programs.

\section{ACKNOWLEDGEMENTS}

Spit for Science: The VCU Student Survey has been supported by Virginia Commonwealth University, P20 AA107828, R37AA011408, K02AA018755, and P50 AA022537 from the National Institute on Alcohol Abuse and Alcoholism, and UL1RR031990 from the National Center for Research Resources and National Institute of Health Roadmap for Medical Research. We thank the VCU students for making this study a success, as well as the many VCU faculty, students, and staff who contributed to the design and implementation of the project. We are grateful to Kenneth S. Kendler for his support of this Spit for Science project.

\section{REFERENCES}

1. Bjartveit, K., and Tverdal, A. (2005). Health consequences of smoking 1-4 cigarettes per day. Tob Control, 14(5), 315-320. http://doi.org/10.1136/tc.2005.011932

2. Mathiesen, E. F., Nome, S., Eisemann, M., and Richter, J. (2012). Drinking patterns, psychological distress and quality of life in a Norwegian general population-based sample. Qual Life Res, 21(9), 1527-1536. http://doi.org/10.1007/s11136-011-0080-8

3. Perkins, H. W. (2002). Surveying the damage: a review of research on consequences of alcohol misuse in college populations. $J$ Stud Alcohol, Supplement(14), 91-100. http://dx.doi.org//10.15288/jsas.2002.s14.91

4. Hingson, R. W., Zha, W., and Weitzman, E. R. (2009). Magnitude of and trends in alcohol-related mortality and morbidity among U.S. college students ages 18-24, 1998-2005. J Stud Alcohol Drugs Suppl, (16), 12-20.

5. Hernandez, L., Rodriguez, A. M., and Spirito, A. (2015). Brief Family-Based Intervention for Substance Abusing Adolescents. Child Adol Psych Cl, 24(3), 585-599. http://doi.org/10.1016/j.chc.2015.02.010

6. Fromme, K., Corbin, W. R., and Kruse, M. I. (2008). Behavioral risks during the transition from high school to college. Dev Psychol, 44(5), 1497-1504. http://doi.org/10.1037/a0012614

7. Hartman, J. D., Patock-Peckham, J. A., Corbin, W. R., Gates, J. R., Leeman, R. F., Luk, J. W., and King, K. M. (2015). Direct and indirect links between parenting styles, self-concealment (secrets), impaired control over drinking and alcohol-related outcomes. Addict Behav, 40, 102-108. http://doi.org/10.1016/j.addbeh.2014.08.009

8. Patock-Peckham, J. A., Cheong, J., Balhorn, M. E., and Nagoshi, C. T. (2001). A social learning perspective: a model of parenting styles, self-regulation, perceived drinking control, and alcohol use and problems. Alcohol Clin Exp Res, 25(9), 12841292.

9. El Ansari, W., Vallentin-Holbech, L., and Stock, C. (2015). Predictors of illicit drug use among university students in Northern Ireland, Wales and England. Global J of Healt Sci, 7(4), 18-29. http://doi.org/10.5539/gjhs.v7n4p18

10. Bachman, J.G. (2002). The Decline of Substance Use in Young Adulthood: Changes in Social Activities, Roles and Beliefs. Mahwah, N.J: Psychol Press.

11. Davis-Kean, P. E. (2005). The Influence of Parent Education and Family Income on Child Achievement: The Indirect Role of Parental Expectations and the Home Environment. J Fam Psychol, 19(2), 294-304. http://doi.org/10.1037/0893-3200.19.2.294

12. He, J., Assanangkornchai, S., Cai, L., and McNeil, E. (2016). Disparities in drinking patterns and risks among ethnic majority and minority groups in China: The roles of acculturation, religion, family and friends. Drug Alcohol Depen, 159, $198-206$. http://doi.org/10.1016/j.drugalcdep.2015.12.028 
13. Lamborn, S. D., Mounts, N. S., Steinberg, L., and Dornbusch, S. M. (1991). Patterns of Competence and Adjustment among Adolescents from Authoritative, Authoritarian, Indulgent, and Neglectful Families. Child Dev, 62(5), 1049. http://doi.org/10.1111/1467-8624.ep9112161645

14. Steinberg, L., Lamborn, S. D., Dornbusch, S. M., and Darling, N. (1992). Impact of Parenting Practices on Adolescent Achievement: Authoritative Parenting, School Involvement, and Encouragement to Succeed. Child Dev, 63(5), $1266-1281$. http://doi.org/10.2307/1131532

15. Dick, D., Nasim, A., Edwards, A. C., Salvatore, J., Cho, S. B., Adkins, A., ... and Kendler, K. S. (2014). Spit for Science: launching a longitudinal study of genetic and environmental influences on substance use and emotional health at a large US university. Behav Psych Genet, 5, 47. http://doi.org/10.3389/fgene.2014.00047

16. Harris, P. A., Taylor, R., Thielke, R., Payne, J., Gonzales, N., and Conde, J. G. (2009). Research electronic data capture (REDCap) - A metadata-driven methodology and workflow process for providing translational research informatics support. $J$ Biomed Inform, 42(2), 377-381. http://dx.doi.org/10.1016/j.jbi.2008.08.010

17. Bush, K., Kivlahan, D. R., McDonell, M. B., Fihn, S.D., \& Bradley, K. A. (1998). The AUDIT alcohol consumption questions (AUDIT-C): An effective brief screening test for problem drinking. Arch Intern Med, 158(16), 1789-1795. http://dx.doi.org/10.1001/archinte.158.16.1789

18. Sher, K. J., and Rutledge, P. C. (2007). Heavy drinking across the transition to college: Predicting first-semester heavy drinking from precollege variables. Addict Behav, 32(4), 819-835. http://dx.doi.org/10.1016/j.addbeh.2006.06.024

19. Kendler, K. S., Gardner, C. O., and Prescott, C. A. (1997). Religion, psychopathology, and substance use and abuse; a multimeasure, genetic-epidemiologic study. Am J Pysch, 154(3), 322-329. http://dx.doi.org/10.1176/ajp.154.3.322

20. Berge, J., Sundell, K., Öjehagen, A., and Håkansson, A. (2016). Role of parenting styles in adolescent substance use: results from a Swedish longitudinal cohort study. BMJ Open, 6(1), e008979. http://doi.org/10.1136/bmjopen-2015-008979

21. Parrott, A. (2004). Understanding Drugs and Behaviour. Chichester, West Sussex, Eng: John Wiley and Sons, Inc.

22. Droomers, M., Schrijvers, C., Casswell, S., and Mackenbach, J. (2003). Occupational level of the father and alcohol consumption during adolescence; patterns and predictors. J Epidemiol Commun H, 57(9), 704-710. http://doi.org/10.1136/jech.57.9.704

23. Armsden, G.C., Greenberg, M. T. (1987). The inventory of parent and peer attachment: Individual differences and their relationship to psychological well-being in adolescence. J Youth Adolesc, 16(5), 427-454. http://doi.org/10.1007/BF02202939

24. Humensky, J. L. (2010). Are adolescents with high socioeconomic status more likely to engage in alcohol and illicit drug use in early adulthood? Subst Abuse Treat Pr, 5, 19. http://doi.org/10.1186/1747-597X-5-19

25. Carroll, S. L., Lee, R. E., Kaur, H., Harris, K. J., Strother, M. L., and Huang, T. T.-K. (2006). Smoking, Weight Loss Intention and Obesity-Promoting Behaviors in College Students. J Am Coll Nutr, 25(4), 348-353. http://doi.org/10.1080/07315724.2006.10719545

26. Wang, B., Stanton, B., Li, X., Cottrell, L., Deveaux, L., and Kaljee, L. (2013). The influence of parental monitoring and parent-adolescent communication on Bahamian adolescent risk involvement: A three-year longitudinal examination. Soc Sci Med, 97, 161-169. http://doi.org/10.1016/j.socscimed.2013.08.013

27. Rosnati, R., Iafrate, R., and Scabini, E. (2007). Parent-adolescent communication in foster, inter-country adoptive, and biological Italian families: Gender and generational differences. Int J Psychol, 42(1), 36-45.

http://doi.org/10.1080/00207590500412128

\section{ABOUT THE STUDENT AUTHOR \\ Zackaria Niazi is currently pursuing a B.S. in Biology at Virginia Commonwealth University (VCU). He worked with Spit for Science as an Undergraduate Research Assistant for one year. Currently, he is an Undergraduate Research Assistant for the Service Experiences and Alcohol Preference study at the Virginia Institute for Psychiatric and Behavioral Genetics. In addition to being involved in research, Zackaria is the Vice President of the Health Disparities Organization at VCU.}

\section{PRESS SUMMARY}

Overall, both alcohol and nicotine use among university students have demonstrated a compromising effect on physical health, mental health, and/or social relationships. To help improve future intervention methods, this study sought to find the relationship between parenting styles and alcohol/nicotine use of university students. In addition, it sought to find moderators of the relationship. The results indicate that parenting styles may play little role in the development of alcohol and nicotine use among university students. Additionally, this study found that father education demonstrated borderline significant moderation between Parental Involvement and alcohol use of university students. Gender was found to demonstrate significant moderation between Parental Involvement and nicotine use of university students. No moderators were found between Autonomy Granting and alcohol use, nor Autonomy Granting and nicotine use. 